\title{
Gender-Related Particularities in Acute Myocardial Infarction - a Study on a Patient Cohort from North East Romania
}

\author{
Larisa Anghel $^{1,2}$, Cristina Prisacariu ${ }^{1,2}$, Cătălina Arsenescu Georgescu ${ }^{1,2}$ \\ 1 "Prof. Dr. George I.M. Georgescu" Institute of Cardiovascular Diseases, Iaşi, Romania \\ 2 "Grigore T. Popa" University of Medicine and Pharmacy, Iaşi, Romania
}

\begin{abstract}
Introduction: Cardiovascular disease is the leading cause of death among women irrespective of race or ethnicity, and about half of these deaths are caused by coronary artery disease. Several studies have reported that cardiovascular diseases manifest themself with a delay of about 7-10 years in women and that they have higher in-hospital mortality. It has not yet been established whether female gender itself, through biological and sociocultural differences, represents a risk factor for early in-hospital mortality in ST-segment elevation acute myocardial infarction (STEMI). The aim of our study was to identify the angiographic particularities in women with STEMI from North East Romania. Material and Methods: For one year, 207 (31.7\%) women and $445(68.3 \%)$ men diagnosed with acute myocardial infarction were hospitalized in the Cardiology Clinic of the "Prof. Dr. George I. M. Georgescu" Institute of Cardiovascular Diseases in Iași, Romania. Results: The highest incidence of symptom onset was between 6:00 a.m. and 12:00 a.m., this morning polarization being more obvious in women. Within the first two hours of admission to the hospital, coronary angiography was performed in $78.1 \%$ of men and only $67.3 \%$ of women, the difference being statistically significant $(\mathrm{p}<0.05)$. We found that a large number of women had multivascular coronary disease (47.9\% vs. $42.3 \%$ ). At the same time, we found that left main disease and multivascular disease were more frequent in women than in men (3.8\% vs. $0.7 \%, p=0.001$ for left main plus two-vessel disease, and $19.4 \%$ vs. $14.8 \%, p=0.0005$ for three-vessel disease). Conclusions: In women, coronary events began more frequently in the morning, with atypical symptoms; also, fewer women presented to the hospital within the first 12 hours after the onset of the acute event. Compared to men, women from North East Romania present a higher incidence of multivascular atherosclerotic coronary lessions, indicating a higher severity of STEMI in the female population from this geographical area.
\end{abstract}

Keywords: coronary artery disease, multicoronary lesions, women, in-hospital mortality

\section{ARTICLE HISTORY}

Received: April 11, 2018

Accepted: May 28, 2018

\section{CORRESPONDENCE}

Larisa Anghel

Blv. Carol I nr. 50

700503 Iaşi, Romania

Tel: +40 232211834

E-mail: larisa_med86@yahoo.com 


\section{INTRODUCTION}

Until a few decades ago, cardiovascular diseases and coronary artery diseases were considered the attribute of the male population. Further studies, which included more and more women, indicated that although cardiovascular diseases do not affect less women, they become manifest in this patient population with a delay of about $7-10$ years..$^{1,2}$

Over time, several hypotheses have been formulated to explain the higher in-hospital mortality in females with ST-segment elevation acute myocardial infarction (STEMI) compared to men, such as the presence of more comorbidities or the suboptimal use of reperfusion strategies. $^{3-5}$ It has not yet been established whether female gender itself, through biological and sociocultural differences, represents a risk factor for early in-hospital mortality in STEMI.

The aim of our study was to identify the angiographic particularities in women with STEMI from North East Romania.

\section{MATERIALS AND METHODS}

This is an observational study, which included patients with STEMI admitted to the Cardiology Clinic of the "Prof. Dr. George I.M. Georgescu" Institute of Cardiovascular Diseases, Iași, Romania, between September 1, 2011 and September 1, 2012. During the study period, 652 patients diagnosed with acute myocardial infarction were hospitalized. According to their gender, the patients were divided into two groups: 207 (31.7\%) women and 445 (68.3\%) men.

Only patients who met the first criteria established by the third universal definition of myocardial infarction were included in the study: patients with new or presumed new left bundle branch block and those with pathological ST-segment elevation in at least two concordant leads. ${ }^{6}$ Pathological ST-segment elevation was defined based on its amplitude measured at the J point:

- in leads V2-V3: at least $0.2 \mathrm{mV}(2 \mathrm{~mm})$ in men over 40 years and at least $0.25 \mathrm{mV}(2.5 \mathrm{~mm})$ in men under 40 years; at least $0.15 \mathrm{mV}(1.5 \mathrm{~mm})$ in women;

- in the other leads: at least $0.1 \mathrm{mV}(1 \mathrm{~mm})$.

We used the standard electrocardiogram with 12 leads. Special leads for the right ventricle (V1R-V6R) and posterior leads $\mathrm{V} 7-\mathrm{V} 9$ were added in case of suspicion of inferior myocardial infarction and in patients with normal electrocardiogram on rest but with high clinical suspicion of acute coronary syndrome.
Based on the ST-segment elevation from the concordant leads (defined as groups of leads that look to the same region of the myocardium), infarct location was established as follows:

- anterior myocardial infarction: V1-V6;

- inferior myocardial infarction: DII, DIII, aVF;

- apical/lateral myocardial infarction: DI, aVL;

- inferior-basal (posterior) myocardial infarction: V7V9;

- involvement of the right ventricle: V3R-V6R.

All clinical and paraclinical investigations were performed in the "Prof. Dr. George I.M. Georgescu" Institute of Cardiovascular Diseases, Iași, Romania.

Patients were informed about the study and their written informed consent was obtained. The trial protocol was approved by the Medical Ethics Committee of the "Grigore T. Popa" University of Medicine and Pharmacy, Iași, and was conducted according to the modified Declaration of Helsinki (Somerset West Amendment, 1996).

Statistical analyses were performed using the Statistical Program for Social Sciences (version 17.0 SPSS Inc.). Data were labeled as nominal or quantitative variables. Nominal variables were described using frequencies. Quantitative variables were tested for nominality of distribution by means of Kolmogorov-Smirnov test and were described by median and percentiles or by mean and standard deviation, whenever the case. The frequencies of nominal variables were compared with a chi-square test. Differences in the means and medians or between groups were analyzed using t-test or Mann-Whitney test when appropriate. A p value of $<0.05$ was considered statistically significant.

\section{RESULTS}

\section{PATIENT POPULATION}

Patients included in the study were between 29 and 90 years, and the global median age was $62.65 \pm 11.8$ years. The median age was $68.20 \pm 10.8$ years (limits: $40-90$ years) for females and $60.67 \pm 11.6$ years (limits: $29-89$ years) for men. Most of the patients (68.1\%) included in the study were men.

\section{SYMPTOM ONSET}

Our study indicated a maximum onset of symptoms in the morning, followed by the period between 12:00 and $24: 00$, while the lowest frequency of symptom onset was 
TABLE 1. Symptom onset by time interval and patient gender

\begin{tabular}{llll}
\hline Time interval & Women & Men & P value \\
\hline 06:00-12:00 & $44.4 \%$ & $40.4 \%$ & 0.615 \\
12:00-24:00 & $35.7 \%$ & $37.1 \%$ & 0.962 \\
24:00-06:00 & $18.4 \%$ & $20.9 \%$ & 0.933 \\
Unknown & $1.4 \%$ & $1.6 \%$ & absent \\
\hline
\end{tabular}

registered between 24:00 and 06:00 (Table 1). The onset of symptoms during morning hours (between 06:00 and 12:00), was more frequent in women compared to men; however, this difference was not statistically significant.

\section{CHEST PAIN CHARACTERISTICS}

More than half of the patients from our study (three quarters) had typical chest pain at the onset of the acute coronary event (Figure 1). Interestingly, a higher number of men had typical chest pain compared to women, the difference being statistically significant.

\section{TIME TO PRESENTATION}

Although more than three quarters of the patients reached the intensive care unit within the first 12 hours from the onset of symptoms, fewer women managed to reach the hospital within this time limit compared to men; however, this difference was not statistically significant. The ma-
TABLE 2. Time from onset of symptoms to presentation in the primary $\mathrm{PCl}$ center

\begin{tabular}{llll}
\hline Time interval & Women & Men & P value \\
\hline Less than 120 minutes & $4.4 \%$ & $4.2 \%$ & 0.328 \\
Between 3-12 hours & $67.6 \%$ & $74.5 \%$ & 0.162 \\
More than 12 hours & $28 \%$ & $21.3 \%$ & 0.454 \\
\hline
\end{tabular}

TABLE 3. Localization of ST-segment elevation on the surface ECG

\begin{tabular}{llll}
\hline ST-segment elevation & Women & Men & P value \\
\hline V1-V6 & $63.3 \%$ & $54.4 \%$ & 0.121 \\
D I, aVL & $15.5 \%$ & $18.2 \%$ & 0.562 \\
D II, D III, aVF & $53.1 \%$ & $51.9 \%$ & 0.927 \\
V7-V8 & $16.9 \%$ & $17.8 \%$ & 0.876 \\
aVR & $4.8 \%$ & $6.3 \%$ & 0.345 \\
V1-V3 & $19.9 \%$ & $12.4 \%$ & 0.131 \\
\hline
\end{tabular}

jority of study participants presented within 3-12 hours after the onset of symptoms, and only a small percentage presented in the first three hours (Table 2).

\section{ELECTROCARDIOGRAPHIC LOCALIZATION OF THE MYOCARDIAL INFARCTION}

Anterior myocardial infarction was the most frequent localization of STEMI in our study, regardless of gender $(\mathrm{p}=0.12)$ (Table 3$)$.

$$
p=0.001
$$

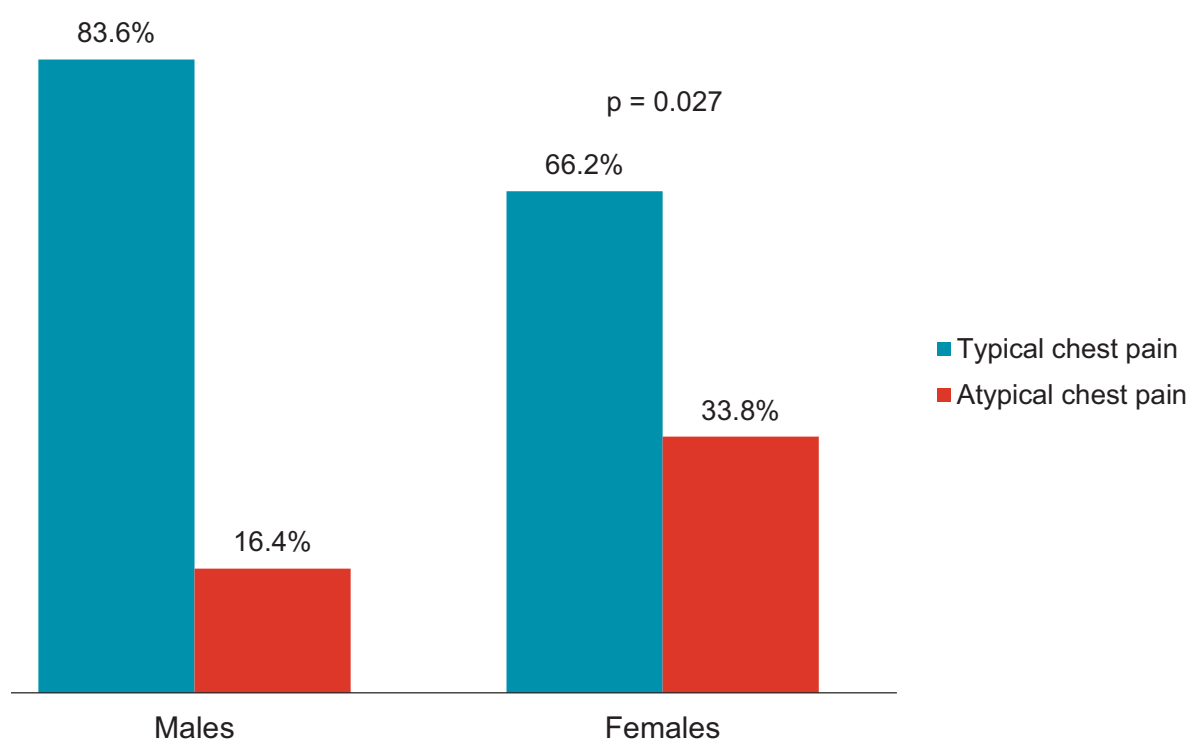

FIGURE 1. Chest pain characteristics for the patients included in the study 


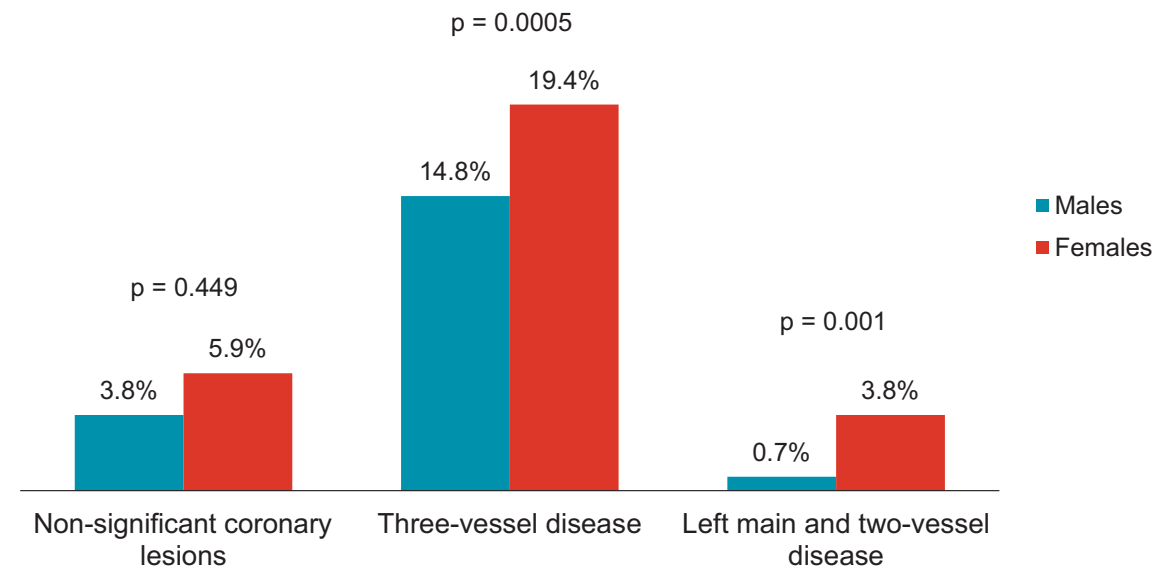

FIGURE 2. Coronary artery lesions for the patients included in the study

\section{CORONARY ANGIOGRAPHY}

Coronary angiography was performed within the first two hours of admission in $78.1 \%$ of men compared to only $67.3 \%$ of women, the difference being statistically significant ( $\mathrm{p}$ <0.05). In a significantly higher number of women, coronary angiography was not performed in the first 24 hours after the onset of symptoms. The majority of patients included in the study had significant atherosclerotic lesions, while non-atherosclerotic lesions occurred only in 6 women (3\%) and in 13 men (2.9\%).

Coronary artery disease was estimated by the number of affected coronary arteries (left main, anterior descending, circumflex, and right coronary artery), regardless of the multitude of segments involved. In both groups, single-vessel disease was the most common, followed by biand three-vessel disease (Figure 2). Three-vessel disease was encountered in $19.4 \%$ of women and $14.8 \%$ of men $(\mathrm{p}=0.0005)$, while the presence of severe atherosclerotic lesions in the left main coronary artery associated with two-vessel disease was recorded in $3.8 \%$ of women compared to only $0.7 \%$ of men $(\mathrm{p}=0.001)$.

In both groups, the left anterior descending coronary artery was affected most frequently, followed by the right coronary artery and the circumflex coronary artery.

\section{DEATH DURING HOSPITALIZATION AND OTHER COMPLICATIONS}

During hospitalization, 37 patients $(5.67 \%)$ enrolled in the study had died. Mortality was higher among women (30 deaths) compared to men (7 deaths), although the difference was not statistically significant $(\mathrm{p}=0.764)$.

We analyzed the correlation between different variables considered as particularities of the female population and the risk of death. Linear regression analysis indicated that there is a highly significant correlation between older age and the risk of death.

This association was also confirmed using Pearson's correlation ( $r=0.210, p<0.01)$ and the ANOVA test ( $p$ $<0.01$ ). On the contrary, body mass index was not associated with a high risk of death $(r=-0.28, p>0.05)$.

At the same time, women developed complications more frequently, such as left ventricular failure, total atrioventricular block, bleeding complications, pericardial effusion, right bundle branch block, and ventricular fibrillation.

\section{DISCUSSIONS}

\section{AGE AND GENDER DISTRIBUTION IN THE STEMI POPULATION}

The mean age of women included in the study (68.2 years) was nearly 8 years higher than that of men (60.67 years), with a highly statistically significant difference between the groups ( $\mathrm{p} \leq 0.001)$. Our results are in accordance with data from the literature, which show that the first episode of acute coronary syndrome occurs after menopause and is delayed with about $6-10$ years in women versus men. ${ }^{7-11}$ The temporal delay in the occurrence of coronary artery disease in women is most likely due to the protective effects of endogenous estrogens. ${ }^{11,12}$

Most men (65.4\%) were aged up to 64 years, the difference between men and women of the same age range being statistically significant ( $\mathrm{p}<0.001)$. At the same time, most of the women $(66.7 \%)$ included in the study were older than 65 years.

These results are similar to those reported by a study that analyzed 13,744 patients with STEMI, who had an av- 
erage age of $61.8 \pm 12.7$ years, with a mean age of $66.6 \pm$ 12.9 years for women and $60.2 \pm 12.3$ years for men, while the number of women aged over 65 was significantly higher than of men. ${ }^{9}$

The analysis of gender distribution revealed a net predominance of men, with a statistically significant difference between the two genders ( $p<0.001)$; this has also been reported by other studies that analyzed this demographic variable. ${ }^{7,13-16}$ In our study, only $31.7 \%$ of patients were women, which is consistent with the current literature indicating that $25-30 \%$ of patients with STEMI are women. ${ }^{7,12}$

\section{GENDER AND CIRCADIAN VARIATIONS OF SYMPTOMS IN STEMI}

Since 1985, numerous studies have indicated a circadian variation of STEMI with a peak of onset between 6:00 and 12:00 in the morning. Subsequent studies have identified the existence of a second peak, between 19:00 and 21:00, in the Asian population, mainly in case of elderly subjects (aged over 80) and possibly for women..17,18

Both in women and men, the highest incidence of symptom onset was recorded in the morning hours, in the interval between 06:00 and 12:00, this morning polarization being more obvious in women, however without a statistically significant difference. Interestingly, the onset of symptoms during the day was rare in men ( $p<0.01$ versus the matinal onset).

\section{LOCALIZATION OF THE MYOCARDIAL INFARCTION AND GENDER DISTRIBUTION}

There are few data in the literature regarding the association between the localization of myocardial infarction and gender distribution. ${ }^{19,20}$ In our study, the most frequent localization of myocardial infarction was anterior, followed by inferior, for both men and women.

We also found that coronary angiography was less frequently performed in women, but the difference compared to men was not statistically significant. This difference could be explained by the higher number of women who reach the hospital after more than 12 hours after the onset of symptoms. Coronary angiography provides the most accurate information for interventional therapy, surgical or drug-only. The three large epicardial coronary arteries are the anterior descending artery (LAD), the circumflex artery (CX), and the right coronary artery (RCA). Coronary artery disease was defined by the presence of a stenosis of more than $50 \%$ in one or more epicardial arteries, al- though less severe stenoses can also be complicated by tearing and thrombus formation with the occurrence of myocardial infarction.

Normal angiographic coronary arteries, non-significant coronary lesions, and non-aterosclerotic lesions were more common in women than in men; however, the difference was not statistically significant. Coronary artery disease was estimated by the number of major epicardial arteries affected, no matter how many segments were involved.

In both groups, unicoronary lesions were most frequently observed, with a 10.6\% higher incidence in men than women.

Generally, multivascular coronary disease is found in $40-65 \%$ of patients with STEMI and is associated with an unfavorable prognosis. ${ }^{21-23}$ In our study, we found that a large number of women had multivascular coronary disease $(47.9 \%$ vs. $42.3 \%$, which included all cases with two-vessel disease, three-vessel disease, and left main associated with two- or three-vessel disease). This observation is in contradiction with most studies that reported a higher prevalence of multicoronary lesions in men. At the same time, we found that left main disease was higher in women than men, which could also explain the higher death rate in the female population in this study.

\section{CONCLUSIONS}

In women, coronary events began more frequently in the morning, with atypical symptoms; also, fewer women presented to the hospital within the first 12 hours from the onset of the acute event. The results of our study showed that, compared to men, women from North East Romania present a higher incidence of multivascular atherosclerotic coronary lessions, indicating a higher severity of STEMI in the female population from this geographical area.

\section{CONFLICT OF INTEREST}

Nothing to declare.

\section{REFERENCES}

1. Benamer $\mathrm{H}$, Tafflet $\mathrm{M}$, Bataille $\mathrm{S}$, et al. Female gender is an independent predictor of in-hospital mortality after STEMI in the era of primary PCI: insights from the Greater Paris Area PCI Registry. EuroIntervention. 2011;6:1073-1079. doi: 10.4244/EIJV6I9A187.

2. Sadowski M, Gasior M, Gierlotka M, Janion M, Polonski L. Gender-related differences in mortality after ST-segment 
elevation myocardial infarction: a large multicentre national registry. EuroIntervention. 2011;6:1068-1072. doi: 10.4244/ EIJV6I9A186.

3. Hillis LD, Smith PK, Anderson JL, et al. 2011 ACCF/AHA Guideline for coronary artery bypass graft surgery: a report of the American College of Cardiology Foundation/American Heart Association Task Force on Practice Guidelines Circulation. J Am Coll Cardiol. 2011;58:e123-e210. doi: 10.1016/j. jacc.2011.08.009.

4. Claassen M, Sybrandy KC, Appelman YE, Asselbergs FW. Gender gap in acute coronary heart disease: myth or reality? World J Cardiol. 2012;4:36-47. doi: 10.4330/wjc.v4.i2.36.

5. Kang SH, Suh JW, Yoon $\mathrm{CH}$, et al. Gender differences in management and mortality of patients with ST-elevation myocardial infarction (from the Korean Acute Myocardial Infarction National Registry). Am J Cardiol. 2012;109:787-793. doi: 10.1016/j.amjcard.2011.11.006.

6. Thygesen K, Alpert JS, Jaffe AS, et al. Third universal definition of myocardial infarction. J Am Coll Cardiol. 2012;60:1581-1598. doi: 10.1016/j.jacc.2012.08.001.

7. Leurent G, Garlantézec R, Auffret V, et al. Gender differences in presentation, management and inhospital outcome in patients with ST-segment elevation myocardial infarction: data from 5000 patients included in the ORBI prospective French regional registry. Arch Cardiovasc Dis. 2014;107:291298. doi: 10.1016/j.acvd.2014.04.005.

8. Chow CK, IslamS, Bautista L, et al. Parental history and myocardial infarction risk across the world: the INTERHEART study. J Am Coll Cardiol. 2011;57:619-627. doi: 10.1016/j. jacc.2010.07.054.

9. Stramba-Badiale M, Fox KM, Priori SG, et al. Cardiovascular diseases in women: a statement from the policy conference of the European Society of Cardiology. Eur Heart J. 2006;27:9941005. doi: 10.1093/eurheartj/ehi819.

10. Von Eisenhart Rothe AF, Albarqouni L, Gärtner C, Walz L, Smenes K, Ladwig KH. Sex specific impact of prodromal chest pain on pre-hospital delay time during an acute myocardial infarction: Findings from the multicenter MEDEA Study with 619 STEMI patients. Int J Cardiol. 2015;201:581-586. doi: 10.1016/j.ijcard.2015.01.067.

11. De Boer SP, Roos-Hesselink JW, van Leeuwen MA, et al. Excess mortality in women compared to men after PCI in STEMI: an analysis of 11,931 patients during 2000-2009. Int J Cardiol. 2014;176:456-463. doi: 10.1016/j.ijcard.2014.07.091.

12. Kuhn L, Page K, Rahman MA, Worrall-Carter L. Gender difference in treatment and mortality of patients with STsegment elevation myocardial infarction admitted to Victorian public hospitals: a retrospective database study. Aust Crit Care. 2015;28:196-202. doi: 10.1016/j.aucc.2015.01.004.

13. Ertelt K, Généreux P, Mintz GS, et al. Clinical profile and impact of family history of premature coronary artery disease on clinical outcomes of patients undergoing primary percutaneous coronary intervention for ST-elevation myocardial infarction: analysis from the HORIZONS-AMI Trial. Cardiovasc Revasc Med. 2014;15:375-380. doi: 10.1016/j. carrev.2014.09.002.

14. Bavishi C, Bangalore S, Patel D, Chatterjee S, Trivedi V, Tamis-Holland JE. Short and long-term mortality in women and men undergoing primary angioplasty: a comprehensive meta-analysis. Int J Cardiol. 2015;198:123-130. doi: 10.1016/j. ijcard.2015.07.001.

15. Velders MA, Boden $H$, van Boven AJ, et al. Influence of gender on ischemic times and outcomes after ST-elevation myocardial infarction. Am J Cardiol. 2013;111:312-318. doi: 10.1016/j.amjcard.2012.10.007.

16. Cenko E, Yoon J, Kedev S, et al. Sex differences in outcomes after STEMI: effect modification by treatment strategy and age. JAMA Intern Med. 2018;178:632-639. doi: 10.1001/ jamainternmed.2018.0514.

17. Itaya H, Takagi T, Sugi K, Nakamura M. Contents of second peak in the circadian variation of acute myocardial infarction in the Japanese population. J Cardiol. 2012;59:147-153. doi: 10.1016/j.jjcc.2011.11.011.

18. Takeda N, Maemura K. Circadian clock and the onset of cardiovascular events. Hypertens Res. 2016;39:383-390. doi: 10.1038/hr.2016.9.

19. Asgar Pour H, Norouzzadeh R, Heidari MR. Gender differences in symptom predictors associated with acute coronary syndrome: a prospective observational study. Int Emerg Nurs. 2016;25:13-18. doi: 10.1016/j.ienj.2015.06.008.

20. O'Donnell S, McKee G, O'Brien F, Mooney M, Moser DK. Gendered symptom presentation in acute coronary syndrome: a cross sectional analysis. Int J Nurs Stud. 2012;49:1325-1332. doi: 10.1016/j.ijnurstu.2012.06.002.

21. Pain TE, Jones DA, Rathod KS, et al. Influence of female sex on long-term mortality after acute coronary syndromes treated by percutaneous coronary intervention: a cohort study of 7304 patients. Coron Artery Dis. 2013;24:183-190. doi: 10.1097/ MCA.ob013e32835d75fo.

22. Lekston A, Tajstra $M$, Gasior $M$, et al. Impact of multivessel coronary disease on one-year clinical outcomes and five-year mortality in patients with ST-elevation myocardial infarction undergoing percutaneous coronary intervention. Kardiol Pol. 2011;69:336-343.

23. Dziewierz A, Siudak Z, Rakowski T, Zasada W, Dubiel JS, Dudek D. Impact of multivessel coronary artery disease and noninfarct-related artery revascularization on outcome of patients with ST-elevation myocardial infarction transferred for primary percutaneous coronary intervention (from the EUROTRANSFER Registry). Am J Cardiol. 2010;106:342-347. doi: 10.1016/j.amjcard.2010.03.029. 